\title{
Gebelikteki Beden İmajının Emzirme Tutumu ve Doğum Sonu Emzirme Sürecine Etkisi
}

\author{
Breastfeeding Attitude of Body Image in Pregnancy and Effect on Breastfeeding Process
}

\author{
Esra GÜNEY ${ }^{1}$, Tuba UÇAR ${ }^{2}$
}

1. Arş. Grv. Esra GÜNEY, Inönü Üniversitesi Sağlık Bilimleri Fakültesi Ebelik Bölümü, Malatya, Türkiye

2. Yrd. Doç. Dr., Inönü Üniversitesi Sağlık Bilimleri Fakültesi, Ebelik Bölümü, Malatya, Türkiye

\section{ÖZET}

Amaç: Araștırmanın amacl, gebelikteki beden imajının emzirme tutumu ve doğum sonu emzirme sürecine etkisini belirlemektir.

Gereçler ve Yöntem: Araştırmanın örneklemini bir kamu hastanesinin Kadın Doğum Polikliniklerine bașvuran 242 gebe oluşturdu. Gebelere ilk görüşmede Kişisel Bilgi Formu, Emzirme Tutumunu Değerlendirme Ölçeği (CYBBÏ̈) ve Çok Yönlü Beden-Benlik Illişkileri Ölçeği (ETDÖ) yüz yüze görüşme yöntemiyle uygulandı. İkinci görüsme doğum sonu altıncı ayda annelere telefonla ulaşılarak yapıldı. Bu görüşmede annelere Emzirme Sürecini Değerlendirme Formu uyguland $(n=113)$. Verilerin analizinde tanımlayıcı istatistiksel yöntemler, Kruskal Wallis testi ve spearman korelasyon analizi kullanıld.

Bulgular: Gebelerin \%61.2 'sinin 18-25 yaş aralı̆̆ında olduğu, $\% 31.4$ 'ünün lise mezunu, \%85.1 'inin çalışmadığ ve \%66.1 'inin orta düzeyde gelire sahip olduğu belirlendi. Gebelerin çoğu (\%81) son trimesterdaydl. Gebelerin ÇYBВIÖ puan ortalama-

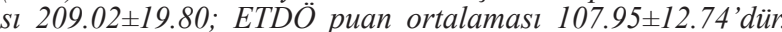
ÇYBBIÖ puan ortalaması ile ETDÖ puan ortalamaları arasinda pozitif yönlü anlaml ilișki saptandl $(p<0.01 ; r=0.249)$. Doğum sonu dönemde annelerin \% 77 'si bebeklerini emzirmiş, emziren annelerin \% 54.1 'si 5-6 ay emzirmis, \% 49.4'ü bebeklerini 6 ay sadece anne sütü ile, \% 50.6 'sı ise karışı olarak beslemişlerdir. Emzirme durumu, emzirme süresi ve bebeğin doğum sonu 6 aylık süre içindeki beslenme șekli ile CYBBIÖ puan ortalamaları arasında anlamlı fark olmadığı belirlendi $(p>0.05)$.

Sonuç: Gebelikte pozitif beden imajina sahip kadınların, emzirme tutumlarının daha yüksek olduğu bulundu. Gebelikteki beden imajının doğum sonu emzirme sürecini ise etkilemediği belirlendi.

Anahtar Kelimeler: gebelik; beden imajl; emzirme tutuтu; doğum sonu emzirme süreci

\section{ABSTRACT}

Objective: The aim of this research is to determine the effect of the body image of pregnancy on the breastfeeding attitude and the postpartum breastfeeding process.

Material and Methods: The sample of the study consisted of 242 pregnant women who applied to the Obstetrics and Gynecology Clinic of a public hospital. Personal information form, Breastfeeding Attitudes of The Evaluation Scale (BAES) and The Multidimensional Body-Self Relations Questionnaire (MBSRQ) were administered by face-to-face interview method at the first visit. At the end of the sixth month, mothers were contacted by telephone and the Breastfeeding Process

\section{İletişim Bilgileri}

Sorumlu Yazar: Esra GÜNEY, Arş. Grv.

Yazışma Adresi: İnönü Üniversitesi, Sağlık Bilimleri Fakültesi, Ebelik Bölümü, 44280, Malatya, Türkiye

E-posta: esra.guney@inonu.edu.tr

Tel: +90 (422) 341-0220

Makale Geliş Tarihi: 19.09.2017

Makale Kabul Tarihi: 05.12.2017

DOI: http://dx.doi.org/10.16948/zktipb.338783
Evaluation Form was applied $(n=113)$. In the analysis of the data, descriptive statistical methods, Kruskal Wallis test and Spearman correlation analysis were used.

Results: It was determined that $61.2 \%$ of pregnants were in the age range of $18-25$ years, $31.4 \%$ of them were high school graduates, $85.1 \%$ were not working and $66.1 \%$ had a moderate level of income. The mean of the mean scores of the pregnant women were $209.02 \pm 19.80$; The average score of BAES is $107.95 \pm 12.74$. There was a significant positive correlation between the mean scores of MBSRQ scale and BAES scores ( $p$ $<0.000, r=0.249)$. During the postnatal period, $77 \%$ of the mothers nursed their babies, $54.1 \%$ of the mothers suckled for 5-6 months, 49.4\% of them fed their babies for 6 months only with breast milk and $50.6 \%$ mixed. It was determined that there was no significant difference between the nutritional status of the breastfeeding status, duration of breastfeeding and the baby during 6 months of postpartum period and MBSRQ points average $(p>0.05)$.

Conclusion: Women with a positive body image in pregnancy were found to have higher breastfeeding attitudes. It was determined that the body image in the pregnancy did not affect the postnatal breastfeeding process.

Keywords: pregnancy; body image; breastfeeding attitude; postpartum breastfeeding process

\section{GİRIŞ}

Dünya Sağl1k Örgütü doğum sonu ilk 6 ay sadece anne sütü önermektedir [1]. Bu önerilere rağmen Türkiye'de "sadece anne sütü" ile beslenme oran1, 0-1 aylık bebeklerde \%57.9 iken, 4-5 aylık bebeklerde ise \%30.1'e gerilemektedir [2].

Emzirme çeşitli nedenlere bağlı olarak erken sonlandırılabilmektedir. Düşük emzirme oranına fiziksel sorunların (ağrı, yorgunluk, bebeğin memeye yerleştirilmesinde zorluk gibi) yanı sıra sosyal ve psikolojik faktörler de neden olabilir [3, 4]. Özellikle annenin anne sütü konusunda bilgi durumu, kendine olan güveni ve emzirmeye doğum öncesi dönemde karar vermiş olması gibi psiko-sosyal faktörler emzirme süresini etkileyebilir [5]. Kadının kendi bedeni ile ilgili algısı da emzirme ile ilişkilidir [3]. Gebelikte kilo alımı ve memelerde dahil vücut görünümündeki değişiklikler sağlıklı gebeliğin bir parçasıdır. Bazı kadınlar gebelik boyunca devam bu değișimleri umursamaz ya da olumlu karșılarken, bazı kadınlar stres olabilir ve kadının beden imajı olumsuz yönde etkilenir [4, 6, 7]. Olumsuz beden imajı gebelikte sık görülür ve doğum sonu döneme kadar uzar [4]. Kadındaki olumsuz beden imajı hem anne hem de bebeğin sağlığını olumsuz etkiler [8, 9]. 
Çünkü bu kadınlar kilo alımını sınırlandırmak için yeterli ve dengeli beslenmez [9]. Türkiye'de yap1lan çalışmalarda gebelikteki beden imajı ile emzirme süreci arasındaki ilişki incelenmemiştir. Yurt dışında yapılan önceki yıllara ait çalışmalarda gebelikte beden imajı ile ilgili endișe yaşayanların bebeklerini daha az emzirdikleri [10] ve daha çok formül mama kullandıkları belirlenmiştir [11]. Yakın zamanda İngiltere'de yapılan bir çalışmada doğum sonu altıncı aydan önce emzirmeyi bırakanların daha çok gebelikte beden imajı kaygısı olan gebeler olduğu bulunmuştur [3].

$\mathrm{Bu}$ çalışmalar emzirmenin başlatılması, sürdürülmesi ve erken bırakılmasında kadının gebelikte beden imajı ile ilgili yaşanan endişelerin etkili olabileceğini göstermektedir. $\mathrm{Bu}$ nedenle gebelerin emzirmeye yönelik tutumlarının ve endişelerinin belirlenmesi sağlık çalışanları tarafından verilecek etkili emzirme danışmanlığının planlanmasına yardımcı olacaktır. Bu çalışmanın amacı gebelikteki beden imajının emzirme tutumu ve doğum sonu emzirme sürecine etkisini belirlemektir.

\section{GEREÇ ve YÖNTEM}

Kesitsel tipte olan araştırma, Ekim 2015-Mart 2016 tarihleri arasinda Malatya'da bir kamu hastanesinin gebe polikliniklerinde yürütüldü. Hastane ildeki düşük, orta ve yüksek riskli gebelere sağlık hizmeti veren ve yılda yaklaşık 20,000 gebenin başvurduğu bir hastanedir. Hastane polikliniklerinde rutin sağlık kontrolleri için bekleyen ve araştırmaya katılmayı kabul eden gebeler çalışma kapsamına alındı. Örneklem büyüklügünün hesaplanmasında OpenEpi, versiyon 3, genel kullanıma açık istatistik yazılımı kullanıldı (http://www.openepi.com) ve ilk 6 ay sadece anne sütü ile beslenme oranı $\% 30.1 \mathrm{ka}-$ bul edildi [2]. Power analizi yapıldığında örneklem büyüklüğü, $\% 5$ yanılg1 düzeyi, $\% 95$ güven aralığında ve $\% 80$ güç ile 318 olarak hesapland1. Ancak 242 gebe araştırmaya katılmaya gönüllü oldu.

Araştırmaya, iletişim kurmada güçlük çekmeyen, 18 yaş ve üzeri primipar 13-42. gebelik haftasında (2. ve 3. trimester) olan tüm gebeler alınmıştır. Araştırmadan dişlanma kriterleri ise gebelikte emzirmeye engel olacak durumlar (ilaç kullanımı gibi), ikiz gebelikler, fetusta bilinen önemli sağlık sorunları (anomaliler gibi), doğum sonunda düşük doğum ağırlıklı (2500 gr ve altında) ya da prematür bebeğe (37. gebelik haftasından önce) sahip olma ve doğum sonu bebeğinden ayrı (küveze alınan gibi) olmadır. Araştırmaya başlamadan önce, tüm gebelerden sözlü izinleri alındı. Ayrıca araştırmanın yürütülebilmesi için kurum izni ve İnönü Üniversitesi Sağlık Bilimleri Bilimsel Araştırma ve Yayın Etiği Kurulu'ndan etik onay alınd1 (No: 2015/8-5). Gebelikteki veriler yüz yüze görüşme yöntemiyle toplandıktan sonra doğum sonu altınc1 ayda annelere telefonla ulaşılarak veriler topland.

Doğum sonu dönemde 37'si çalışmadan ayrilmak istedi, 90 kişiye ulaşılamadı ve 2 kişi ölü doğum yaptığından dolayı, çalışmanın doğum sonu dönemdeki aşaması 113 kişiyle tamamlandı.

\section{Veri Toplama Araçları}

Kişisel Bilgi Formu: Gebelerin bazı bireysel özelliklerini belirlemek amacıyla araştırmacılar tarafından oluşturulmuştur. Formda gebenin yaşı, eğitim düzeyi, çalışma durumu, gelir düzeyi, gebelik öncesi kilosu ve boyu, gebelikteki kilosu ve gebelik haftası gibi bilgiler yer almaktadır. Beden Kitle İndeksi (BKİ) hesaplanırken Vücut A ̆ğılı̆̆1 (kg)/Boy (m)2 formülü kullanıldı ve Dünya Sağlık Örgütü referans değerleri esas alınarak sinıflandırıldı [12].

Emzirme Tutumunu Değerlendirme Ölçeği (ETDÖ): Arslan (1999) tarafından geliştirilen ölçek annelerin emzirme tutumlarını değerlendirmek amacıyla kullanılmaktadır. Ölçekte, emzirme tutumunu etkileyebilecek, annenin kendisine ait emzirme tutumu, annenin diğer kişilerle ilgili emzirme tutumu (eşinin, aile ve yakın çevrenin, sağlık personelinin), toplum olarak emzirme ile ilgili tutumlar, kadına özgü bir işlev olarak emzirme gibi özelliklere yer verilmiştir. Kırk altı sorudan oluşan ölçek 5'li likert tiptedir. Ölçekten alınabilecek en yüksek puan 184 'tür. Ölçekten alınan puan yükseldikçe annelerin emzirmeye ilișkin tutumları olumlu olarak değerlendirilmektedir. Ölçeğin Cronbach's alfa değeri 0.63 olarak bildirilmiştir [13].

Çok Yönlü Beden - Benlik İlişkileri Ölçeği (ÇYBBİÖ): Ölçek 1984 yılında Winstead ve Cash (1984) tarafından geliştirilmiştir [14]. Türkçe geçerlik güvenirlilik çalışması Doğan ve Doğan (1992) tarafından yapılmıştır. Beden imajının yapısını ve kişinin kendi tutumsal yönlerini belirlemek için geliştirilmiş bir kendini değerlendirme ölçeğidir. Ölçek 7 alt boyuttan oluşmaktadır. Bunlar;

1. Görünüşü değerlendirme,

2. Görünüş yönelimi,

3. Fiziksel yeterliliği değerlendirme,

4. Fiziksel yeterlik yönelimi,

5. Sağlık değerlendirmesi,

6. Sağl1k yönelimi,

7. Beden alanlarından doyum.

Beşli likert tipindeki ölçek 57 maddeden oluşmaktadır. Ölçekten toplam en az 57, en çok 285 puan alınabilir. Yükselen puanlar sağ lıklı bir beden ve yüksek beden imajını gösterir. Ölçeğin Cronbach's alfa katsayısı 0.94 olarak saptanmıştır [15].

Emzirme Sürecini Değerlendirme Formu: $\mathrm{Bu}$ form annelerin doğum sonu dönemde emzirme süreci değerlendirmek amacıyla araştırmacılar tarafından oluşturulmuştur. Formda annenin doğum sonu kilosu, yenidoğanın beslenme şekli ve emzirmeyi engelleyen durumlar sorulmaktadır.

\section{Verilerin Analizi}

Araştırmanın verileri SPSS 16.0 for Windows yazılımı (SPSS, Chicago, Il, USA) ile değerlendirildi. Verilerin normal dağılımına uygunluğu Kolmogrov-Smirnov testi ile değerlendirildi. Veriler normal dağılım göstermediği için non-parametrik testlerden Mann-Whitney U, Kruskal Walls testleri ve Spearman korelasyon analizi kullanıldı. Verilerin istatistiksel analizinde tanımlayıc istatistiksel 
yöntemlerden say1, yüzde, ortalama, standart sapma kullanıldı. Sonuçlar \% 95'lik güven aralığında, anlamlılık $\mathrm{p}<0.05$ düzeyinde değerlendirildi.

\section{BULGULAR}

Gebelerin tanımlayıcı özellikleri Tablo 1'de verildi. Gebelerin \%61.2'sinin 18-25 yaş aral1ğında olduğu [(Ort. \pm SS; $25.04 \pm 4.68)$ (min:18; max:40)], \%31.4'ünün lise mezunu, \%85.1'inin çalışmadığ1, \%66.1'inin gelirinin giderine eşit olduğu, $\% 80.6$ 'sının plansız gebe kaldığ 1 , \%81.0'inin 3. trimesterda olduğu belirlendi. Gebelik öncesi BKİ değerlerine göre \%69.8'inin normal, doğum sonu ise \%49.6'sının normal kiloda olduğu bulundu. Gebelik boyunca alınan kilo ortalama $10.85 \pm 5.19 \mathrm{~kg}$ 'dir (Tablo 1).

Tablo 1: Gebelerin tanımlayıcı özellikleri $(n=242)$.

\begin{tabular}{|c|c|c|}
\hline Özellikler & n & $\%$ \\
\hline \multicolumn{3}{|l|}{ Yaş (yıl) } \\
\hline $18-25$ & 148 & 61.2 \\
\hline $26-32$ & 70 & 28.9 \\
\hline $33-41$ & 24 & 9.9 \\
\hline \multicolumn{3}{|l|}{ Eğitim düzeyi } \\
\hline İlkokul mezunu & 37 & 15.3 \\
\hline Ortaokul mezunu & 73 & 30.2 \\
\hline Lise mezunu & 76 & 31.4 \\
\hline Üniversite mezunu & 56 & 23.1 \\
\hline \multicolumn{3}{|l|}{ Çalışma durumu } \\
\hline Çalışıyor & 36 & 14.9 \\
\hline Çalışmıyor & 206 & 85.1 \\
\hline \multicolumn{3}{|l|}{ Gelir düzeyi } \\
\hline Gelir giderden az & 51 & 21.1 \\
\hline Gelir gidere eşit & 160 & 66.1 \\
\hline Gelir giderden fazla & 31 & 12.8 \\
\hline \multicolumn{3}{|l|}{ Gebeliğin planlanması } \\
\hline Planlı & 195 & 80.6 \\
\hline Plansız & 47 & 19.4 \\
\hline \multicolumn{3}{|l|}{ Gebelik haftası } \\
\hline 2. trimester & 46 & 19.0 \\
\hline 3. trimester & 196 & 81.0 \\
\hline \multicolumn{3}{|l|}{ Gebelikten önce ВKi } \\
\hline Zayıf (BKi<18.5) & 20 & 8.3 \\
\hline Normal (BKi =18.5-24.9) & 169 & 69.8 \\
\hline Kilolu (BKi =25-29.9) & 46 & 19.0 \\
\hline Obez $($ BKi >30) & 7 & 2.9 \\
\hline \multicolumn{3}{|c|}{ Gebelikte alınan kilo (Ort. $\pm S S ; 10.85 \pm 5.19$ ) } \\
\hline \multicolumn{3}{|l|}{ Doğum sonu BKi (n=113) } \\
\hline Zayıf (BKİ <18.5) & 2 & 1.8 \\
\hline Normal (BKi =18.5-24.9) & 56 & 49.6 \\
\hline Kilolu (BKi =25-29.9) & 41 & 36.3 \\
\hline Obez (BKi >30) & 14 & 12.4 \\
\hline
\end{tabular}

Gebelerin ÇYBBİÖ toplam puan ortalamas1 209.02 \pm 19.80 ; ETDÖ toplam puan ortalamas1 $107.95 \pm 12.74$ 'dür. Gebelerin CYBBİÖ toplam ve alt boyutlarının puan ortalamaları ile ETDÖ arasindaki korelasyon katsayıları Tablo 2'de verildi. ÇYBBİÖ ölçeğinin alt boyutlarından beden alanlarında doyum alt boyutu en yüksek puanı $(4.06 \pm 0.72)$ almıştır. Sonra sırasıyla görünüş değerlendirme (3.81 \pm 0.53$)$, görünüş yönelimi $(3.78 \pm 0.47)$, sağl1k yönelimi $(3.73 \pm 0.46)$, sağlı değerlendirmesi (3.64 \pm 0.54$)$, fiziksel yeterliliğini değerlendirme (3.57 \pm 0.55$)$, fiziksel yeterlilik yönelimi $(3.04 \pm 0.52)$ yer almaktadır. ÇYBBİÖ'nün alt boyutlarından görünüş değerlendirme, görünüş yönelimi, fiziksel yeterliliğini değerlendirme, sağlık değerlendirmesi ve sağlık yönelimi ile ETDÖ arasında pozitif yönde anlamlı ilişki olduğu belirlendi $(p<0.05)$ (Tablo 2).

Tablo 2: Çok Yönlü Beden - Benlik İlişkileri Ölçeği toplam ve alt boyutlarının puan ortalamaları ile Emzirme Tutumunu Değerlendirme Ölçeği arasındaki korelasyon katsayıları $(n=242)$.

\begin{tabular}{|l|c|c|c|}
\hline & & \multicolumn{2}{|c|}{ ETDÖ } \\
\cline { 3 - 4 } & Ort. \pm SS & $r^{*}$ & p \\
\hline Görünüş Değerlendirme & $3.81 \pm 0.53$ & 0.315 & 0.000 \\
\hline Görünüş Yönelimi & $3.78 \pm 0.47$ & 0.289 & 0.000 \\
\hline Fiziksel Yeterliliğini Değer- & $3.57 \pm 0.55$ & 0.161 & 0.012 \\
\hline lendirme & $3.04 \pm 0.52$ & -0.006 & 0.932 \\
\hline Fiziksel Yeterlilik Yönelimi & $3.64 \pm 0.54$ & 0.245 & 0.000 \\
\hline Sağlık Değerlendirmesi & $3.73 \pm 0.46$ & 0.173 & 0.007 \\
\hline Sağlık Yönelimi & 19.80 & 0.249 & 0.000 \\
\hline Beden Alanlarında Doyum & $4.06 \pm 0.72$ & 0.055 & 0.391 \\
\hline ÇYBBiö toplam & $209.02 \pm$ & 0.000 \\
\hline
\end{tabular}

*: Spearman Korelasyon analizi, ÇYBBiö: Çok Yönlü Beden - Benlik ilişkileri Ölçeği, ETDÖ: Emzirme Tutumunu Değerlendirme Ölçeği

Doğum sonu emzirme ile ilgili bazı değişkenlere göre ÇYBBİÖ puan ortalamalarının karşılaştııılmas1 Tablo 4'de verildi. Doğum sonu annelerin \% $\% 7$ 'si bebeklerini emzirmis, emziren annelerin \%54.1'si 5-6 ay emzirmiş, \%49.4'ü bebeklerini ilk 6 ay sadece anne sütü ile, \%50.6'sı ise karışık olarak beslemişlerdir. Emzirme durumu, emzirme süresi ve bebeğin doğum sonu 6 aylık süre içindeki beslenme şekline göre ÇYBBIÖ puan ortalamaları arasındaki farkın istatistiksel olarak anlamlı olmadı $\breve{g} 1$ belirlendi ( $p>0.05)$ (Tablo 3).

Tablo 3: Doğum sonu emzirme ile ilgili bazı değişkenlere göre ÇYBBiö puan ortalamalarının karşılaştırılması $(n=113)$.

\begin{tabular}{|c|c|c|c|}
\hline & n (\%) & $\begin{array}{l}\text { ÇYвBї̈ } \\
\text { Ort. } \pm \text { SS }\end{array}$ & Test \\
\hline $\begin{array}{l}\text { Emzirme Durumu } \\
\text { Emziren } \\
\text { Emzirmeyen }\end{array}$ & $\begin{array}{l}87(77.0) \\
26(23.0)\end{array}$ & $\begin{array}{l}210.08 \pm 20.45 \\
213.26 \pm 23.71\end{array}$ & $\begin{array}{c}U=946.00 \\
p=0.207\end{array}$ \\
\hline $\begin{array}{l}\text { Emzirme Süresi }(\mathbf{n = 8 7}) \\
1-2 \text { ay } \\
3-4 \text { ay } \\
5-6 \text { ay }\end{array}$ & $\begin{array}{l}14(16.1) \\
26(29.8) \\
47(54.1)\end{array}$ & $\begin{array}{l}202.64 \pm 12.06 \\
209.23 \pm 18.32 \\
212.76 \pm 23.10\end{array}$ & $\begin{array}{c}K W=2.24 \\
p=0.326\end{array}$ \\
\hline $\begin{array}{l}\text { Bebeğin beslenme şekli }(n=87) \\
6 \text { ay sadece anne sütü } \\
\text { Karışık beslenme }\end{array}$ & $\begin{array}{l}43(49.4) \\
44(50.6)\end{array}$ & $\begin{array}{l}211.88 \pm 22.89 \\
208.32 \pm 17.83\end{array}$ & $\begin{array}{c}U=899.50 \\
p=0.693\end{array}$ \\
\hline
\end{tabular}


Doğum sonu emzirmeme nedenleri değerlendirilen annelerin emzirmeme nedenlerinden anne sütünün yeterli olmaması (\%31.9), bebeğin doymaması (\%29.2), bebekte yetersiz kilo alımı (\%16.8), meme ucu çatlağ1 (\%14.2), bebeğin emmek istememesi (\%9.7), annenin emzirme zaman aralığını bilmemesi (\%7.1), emzirmeye engel sağlık problemi (\%4.4) ve bebeği memeye yerleştirmede zorluk yaşanması (\%3.5) olarak belirlendi (Tablo 4).

Tablo 4: Doğum sonu emzirmeme nedenleri ( $n=113)$.

\begin{tabular}{|l|c|c|}
\hline Emzirmeme nedenleri $^{*}$ & $\mathbf{n}$ & \% \\
Sütün yeterli olmaması & 36 & 31.9 \\
Bebeğin doymaması & 33 & 29.2 \\
Bebeğin yeterli kilo almaması & 19 & 16.8 \\
Meme ucu çatlağı & 16 & 14.2 \\
Bebeğin emmek istememesi & 11 & 9.7 \\
Emzirme zaman aralığını öğrenememe & 8 & 7.1 \\
Emzirmeye engel sağlık problemi & 5 & 4.4 \\
Emzirme sırasında ağrı & 5 & 4.4 \\
Memeye yerleştirmede zorluk & 4 & 3.5 \\
\hline
\end{tabular}

*: Katılımcılar birden fazla seçenek işaretlemişlerdir.

\section{TARTIŞMA}

Gebelikte önerilen şekilde kilo artışı ve vücut şeklinde değişiklik beklenen sağlıklı bir süreç olmasına rağmen, kilo artışı ve gebelikteki görünümleri hakkındaki endişelenen kadınların sayısı gün gittikçe artmaktadır. Bu da gebelikte olumsuz beden imajının artma riskini beraberinde getirmektedir [16].Gebeliğin ilerlemesiyle beden imajı negatif olarak etkilenirken, bu durumun postpartum dönemde maksimum seviyeye ulaştığ belirtilmiştir [4]. Gebelikteki beden imajının emzirme tutumu ve doğum sonu emzirme sürecine etkisinin incelendiği bu çalışmada, gebelikte beden imajı puan ortalamaları olumlu olarak arttıkça doğum sonu dönemdeki emzirmeye ilişkin tutumumda olumlu olarak arttığ saptand1 $(\mathrm{p}<0.05)$ (Tablo 2; Bulgular syf 9).

Bu sonuca paralel olarak Harris'ın (1990) yaptığ çalışmada, gebelikte değişen vücut şeklinden dolay1 memnuniyet düzeyi yüksek olan kadınların, bu değişiklikten kaynaklanan memnuniyet düzeyi düşük olan kadınlara göre emzirmeyi daha çok tercih ettiklerini belirtmiştir [17]. Aynı şekilde Tayvan' da yapılan bir çalışma sonucunda da, gebelik öncesi pozitif beden imajına sahip olan kadınların, doğum sonu dönemde emzirmeyi planlama oranlarının daha yüksek bulunduğu belirtilmiştir [18]. İngiltere'de daha önce yapılan bir çalışma sonucuna göre, gebelikte vücut şekilleri ve kilo alımlarıyla ilgili endişe yaşayan kadınların, emzirmeye eğilimlerinin daha az olduğu belirtilmiştir [10].

Bu çalışma sonuçları, elde ettiğimiz araştırma bulgusunu desteklemektedir. Ancak, araştırma sonucunda elde ettiğimiz bulguların aksini ortaya koyan bazı çalışmalar da mevcuttur. Huang ve ark. (2004) yapmış oldukları çalışmada, gebelikte pozitif beden imajına sahip kadınlar ile gebelikte negatif beden imajına sahip kadınlar emzirme tutumları yönünden karşılaştırılmış; beden imajı yüksek olan kadınların bebeklerini biberonla besleme oranlarının daha yüksek, emzirerek besleme oranlarının daha düşük olduğu bulunmuştur [4]. Gebelikte beden imajı düşük olan kadınların ise bebeklerini emzirerek beslenme oranlarının daha yüksek olduğu bulunmuştur. Yine Barnes'e (1997) göre, vücut şekliyle ilgili daha fazla kayg1 yaşayan gebelerin, anne sütü ile emzirmeye yönelik kaygıları daha azdır [10]. Brown ve ark., (2015) yapmış oldukları çalışma bulgularına göre, gebelikte beden imajı endişesi yaşayanların doğum sonu dönemde daha fazla hazır mama kullanmayı ve emzirme sürecini daha kısa tutmayı planladıklarını ortaya koymuştur [3].

Başka bir çalışmada da beden imajı endişesi daha yüksek olan gebelerin hazır mama kullanmaya eğilimlerinin daha yüksek olduğu veya emzirme sürecini daha kısa tutmayı amaçladıkları ortaya konulmuştur [19]. Hughes (1984) ise doğum sonu emzirmede başarılı olan kadınlar ile başarısız olan kadınların gebelikteki beden imajı arasında anlamlı bir fark bulmamıştır [20]. Çalışma sonuçlarındaki farklılıklar emzirmeye bakış açısının kültürel olarak toplumdan topluma farklı anlamlar taşımasından kaynaklaniyor olabilir. Toplumumuzda emzirmenin kutsal bir görev olarak görülmesi ve bundan dolay1 emzirmenin beden imajından tamamen bağımsız bir olgu olarak karşılanması elde ettiğimiz bulguyu açıklar niteliktedir.

Çalışmamızda doğum sonu emzirme durumu, emzirme süresi ve bebeğin beslenme şekli ile beden imajı arasında anlamlı ilişki olmadığı bulundu (p>0.05) (Tablo 3 Bulgular syf 10). Bu sonuç, kadının gebelikte sahip olduğu beden imajının doğum sonu dönemde emzirme sürecinde etkili olmadığını göstermektedir. Bu sonucun araştırmamızda beden imajının gebelik dönenimde değerlendirilmesinden kaynaklandığ1 düşünülmektedir. Bununla birlikte doğum sonu dönemde hızla değişen beden imajının emzirme süreci üzerinde daha fazla etkili olabileceği de göz önünde bulundurulmalıdır. Bu nedenle doğum sonu emzirme süreci değerlendirilirken beden imajının da doğum sonu değerlendirilmesi daha uygun olacaktır.

Çalışmamızda elde edilen diğer bulgulara göre, annelerin bebeklerini emzirmeme nedenleri arasinda annenin sütünü yeterli olmaması (\%31.9), bebeğin doymamas1 (\% 29.2), bebekte yetersiz kilo alım1 (\% 16.8), meme ucu çatlağ 1 (\% 14.2), bebeğin emmek istememesi (\% 9.7), annenin emzirme zaman aralığını bilmemesi (\% 7.1), emzirmeye engel sağlık problemi (\% 4.4) ve bebeği memeye yerleştirmede zorluk yaşanması (\%3.5) olarak belirtilmiştir (Tablo 4 Bulgular syf 10). Brown ve ark., (2015) yapmış oldukları çalışmada doğum sonu ilk 6 ayda emzirmeyi bırakma nedenleri belirlenmiş ve ilk sırada 'emzirmede zorlanma' (sütün yetersiz olmasından ve işlemin yorucu olmasından kaynaklanan) ağrılı (ağrı, enfeksiyon), rahatsız edici (anneye hazır 
beslenmeden daha fazla sorumluluk yüklediğinden annelik yaşam tarzına daha çok müdahale anlamına gelmektedir), vücut imgesi (göğüslerin görünümünden hoşlanmama), utanç (başkalarının veya toplumun önünde emzirmeyi sevmeme), çevresel bask1 (aileden, partnerden kaynakl1), yetersiz destek (zayıf profesyonel destek) ve medikal sebepler olarak belirtilmiştir [3]. Genel olarak bakıldığında emzirmeyi bırakma tüm kadınlarda benzer nedenlerle olmaktadir.

Çalışma bulgularına göre, gebelikte olumlu beden imajı yüksek olan kadınların, emzirme tutumlarının daha yüksek olduğu bulundu. Ancak gebelikteki beden imajının doğum sonu emzirme sürecini etkilemediği belirlendi. Doğum sonu emzirme sürecine etki eden faktörlerin araştırılmasında, doğum sonu beden imajının da değerlendirilmesi ve bu alanda daha fazla araştırma yapılmasına ihtiyaç vardır.

\section{$K A Y N A K L A R$}

1. World Health Organization (WHO) Infant and young child feding. Fact sheet Updated July 2017 http://www.who.int/mediacentre/ factsheets/fs342/en/

2. Türkiye Nüfus ve Sağllk Araştırması Hacettepe Üniversitesi Nüfus Etütleri Enstitüsü Ankara, 2013.

3. Brown A, Ranje J, Warren L. Body image concerns during pregnancy are associated with a shorter breast feeding duration. Midwifery. 2015;31:80-9.

4. Huang HC, Wang SY, Chen CH. Body image, maternal-fetal attachment,

and choice of infant feeding method: a study in Taiwan. BIRTH $2004 ; 31(3): 5-12$

5. Yanıkkerem E, Ay S, Göker A. Primipar ve Multipar Gebelerin Emzirme Tutumu ve Yaşadıklar l Endişeler. Van Tip Dergisi. 2014;21(1):6-16.

6. Clark A, Skouteris H, Wertheim EH, Paxton SJ, Milgrom J. My baby body: A qualitative insight into women's body-related experiences and mood during pregnancy and the postpartum. J Reprod Infant Psychol. 2009;27(4):330-45.

7. Kamysheva E, Skouteris H, Wertheim EH, Paxton SJ, Milgrom $J$. Examination of a multi-factorial model of body-related experiences during pregnancy: The relationships among physical symptoms, sleep quality, depression, self-esteem, and negative body attitudes. Body Image. 2008;5:152-63.

8. Hauff LE, Demerath EW. Body image concerns and reduced breastfeeding duration

in primiparous overweight and obese women. Am J Hum Biol. 2012;24: 339-49.

9. Loth KA, Bauer KW, Wall M, Berge J, Neumark-Sztainer D. Body satisfaction during pregnancy. Body Image. 2011; 8(3): 297-300.

10. Barnes J, Stein A, Smith T, Pollock JI. Extreme attitudes to body shape, social and psychological factors and a reluctance to breast feed. J R Soc Med. 1997;90:551-559.

11. Foster SF, Slade P, Wilson K. Body image, maternal fetal attachment and breast feeding. J Psychosom Res. 1996;41(2):181-4.

12. World Health Organization (WHO) Body mass index - BMI. http://www.euro.who.int/en/health-topics/disease-prevention/nutrition/a-healthy-lifestyle/body-mass-index-bmi

13. Arslan H. Emzirme Tutumunu Değerlendirme Ölçeği Geliştirme, Hemşirelik Forumu. 1999;2(3):132-6.

14. Winstead BA, Cash TF. Reliability and Validity of the Body-Self Questionnaire: A New Measure of Body Image. Paper presented at the meeting of the Southeastern Psychological Association, New Orleans, Louisiana. 1984, March 19-21.

15. Doğan $O$, Doğan S. Çok yönlü beden-self ilişkileri ölçeği el kitabl. Sivas Cumhuriyet Üniversitesi Yayınları.1992:8-29.

16. Skouteris H, Carr R, Wertheim EH, Paxton SJ, Duncombe D. A prospective study of factors that lead to body dissatisfaction during pregnancy. Body Image. 2005;2:347-61.

17. Harris M. Is love seen as different for the obese? J Appl Soc Psychol. 1990;20:1209-24.

18. Larsson $G$, Andersson-Ellstrom A. Experiences of pregnancy-related body shape changes and of breast-feeding in women with a history of eating disorders. Eur Eat Disord Rev. 2003;11:116-24.

19. Rojjanasrirat W, Sousa VD. Perceptions of breastfeeding and planned return to work or school among low income pregnant women in the USA. J Clin Nurs. 2010;19:2014-22.

20. Hughes R. Satisfaction with one's body and success in breastfeeding. Issues Compr Pediatr Nurs. 1984:141-53. 